\title{
GMR
}

\section{Fis in}

\section{Molecular cloning and expression analysis of MAT1 gene in black tiger shrimp (Penaeus monodon)}

\author{
Y. Wang ${ }^{1,2 *}$, M.J. Fu' ${ }^{1,3 *}$, C. Zhao ${ }^{1,3}$, W.Y. Bao ${ }^{3}$, F.L. Zhou ${ }^{1,3}$, Q.B. Yang ${ }^{1,3,4}$, \\ S.G. Jiang ${ }^{1,3}$ and L.H. Qiu ${ }^{1,3}$ \\ ${ }^{1}$ South China Sea Fisheries Research Institute, Chinese Academy of Fishery Sciences, \\ Guangzhou, China \\ ${ }^{2}$ College of Aqua-Life Science and Technology, Shanghai Ocean University, \\ Shanghai, China \\ ${ }^{3}$ Key Laboratory of South China Sea Fishery Resources Exploitation \& Utilization, \\ Ministry of Agriculture, College of Environmental Science and Engineering, \\ Yangzhou University, Guangzhou, China \\ ${ }^{4}$ Tropical Aquaculture Research and Development Center of South China Sea \\ Fisheries Research Institute, Sanya, China \\ *These authors contributed equally to this study. \\ Corresponding author: L.H. Qiu \\ E-mail: qiu902@yahoo.com
}

Genet. Mol. Res. 15 (1): gmr.15017367

Received August 5, 2015

Accepted November 5, 2015

Published February 5, 2016

DOI http://dx.doi.org/10.4238/gmr.15017367

ABSTRACT. MAT1 (ménage à trois 1), an assembly factor and targeting subunit of the CDK-dependent kinase (CAK), can regulate the cell cycle, transcription, and DNA repair. This study was intended to investigate the role of MAT1 in the reproductive maturation of black tiger shrimp (Penaeus monodon). In this study, the P. monodon MAT1 (PmMAT1) gene was identified and characterized. The full-length cDNA of PmMAT1 was 1490 $\mathrm{bp}$ in length with an open-reading frame of $993 \mathrm{bp}$ corresponding to 330 amino acids. The temporal expression of PmMAT1 in various tissues was measured by quantitative real-time PCR with the highest expression 
observed in ovaries. In the ovaries, the PmMAT1 gene was continuously but differentially expressed during the maturation stages. Comparative analyses of MAT1, CDK7, and cyclin $\mathrm{H}$ in the CAK complex of $P$. monodon indicated that the expression of $C D K 7$ and cyclin $H$ coincided with that of MAT1 during the ovary maturation stages. Serotonin (5-HT) injection promoted the expression level of PmMAT1 in the ovaries of shrimp at 6-48 $\mathrm{h}$ post-injection. These results indicate that PmMat1 plays a prominent role in the process of ovarian maturation.

Key words: Cloning; PmMAT1; Quantitative real-time PCR; 5-HT; Black tiger shrimp (Penaeus monodon)

\section{INTRODUCTION}

Cell division is a fundamental process in all unicellular and multicellular organisms (Korsisaari, 2002). Cell cycle progression is regulated by the sequential functions of cyclindependent kinases (CDKs). CDK activation requires phosphorylation of a key residue by the CDK-dependent kinase (CAK; Kaldis et al., 1998). The CAK consists of CDK7 (Levedakou et al., 1994; Wu et al., 1994), cyclin H (Fisher and Morgan, 1994), and the RING finger protein MAT1 (Fisher et al., 1995; Tassan et al., 1995; Yee et al., 1995). CDK7 is activated by cyclin $\mathrm{H}$, whereas MAT1 modulates the substrate specificity of the complex (Yankulov and Bentley, 1997). MAT1 was originally identified as an assembly factor promoting a stable interaction between CDK7 and cyclin H, increasing the activity of CDK7-Cyclin H complex (Devault et al., 1995; Fisher et al., 1995; Tassan et al., 1995). CAK controls cell cycle progression by catalyzing T-loop phosphorylation of CDKs (Nigg, 1996; Kaldis, 1999), and regulates transcription by acting as a kinase of general transcription factor TFIIH to phosphorylate the carboxyl-terminal domain (CTD) of the largest subunit of RNA polymerase II (Hoeijmakers et al., 1996; Kaldis, 1999).

In vitro, the mammalian CAK has been shown to phosphorylate and activate CDK1, CDK2, CDK3, CDK4, and CDK6 (Kaldis, 1999). MAT1 modulates CAK substrate specificity in the regulation of $\mathrm{G} 1$ exit (Wu et al., 2001). Deletion of MAT1 by retrovirus-MAT1 antisense decreases CAK phosphorylation of $\mathrm{pRb}$ and induces $\mathrm{G} 1$ arrest in osteosarcoma cells (Wu et al., 2001). In the mouse heart, abrogation of MAT1 led to a decrease in CDK7 activity and to a general defect in transcriptional co-activation by PGC-1 family members (Sano et al., 2007). MAT1-deficient mice exhibit peri-implantation lethality; the homozygous mutant blastocysts fail to maintain/expand the inner cell mass in culture (Rossi et al., 2001). Postnatal deletion in the testis results in the loss of spermatagonial stem cells, whereas cardiac-specific MAT1 mutants develop heart failure secondary to mitochondrial dysfunction (Inamoto et al., 1997; Sano et al., 2007). The early embryonic lethality of MAT1-null embryos and the requirement for MAT1 in spermatagonial stem cell maintenance suggest that MAT1 modulates transcriptional programs that are essential for stem cell maintenance (Patel and Simon, 2010). Loss of MAT1 in mouse embryonic fibroblasts promotes adipogenesis by decreasing the inhibitory phosphorylation of proliferator-activated receptor $\mathrm{Y}$ (Helenius et al., 2009). These varying phenotypes suggest that MAT1 plays a prominent role in cell survival or transcription.

Although eyestalk ablation is practically used to induce ovarian maturation of the black tiger shrimp ( $P$. monodon), such technique can also lead to an eventual loss in egg quality and death 
of the spawners (Benzie, 1998). Research on the cell cycle regulation can improve the knowledge of molecular mechanisms controlling the development and maturation of ovaries/oocytes in $P$. monodon (Phinyo et al., 2014). To date, the regulation of oocyte maturation in crustaceans is poorly understood as compared to that in other oviparous animals. The present study was intended to provide theoretical support for an alternative approach to trigger the reproductive maturation of black tiger shrimp via conducting functional analysis of MAT1 (PmMat1). To examine the molecular mechanisms of MAT1 involvement in the ovarian (and oocyte) development of $P$. monodon, the MAT1 gene was cloned, the expression patterns of PmMAT1 in different tissues and ovarian mature stages were investigated, and the expression features of $C D K 7$ and cyclin $\mathrm{H}$ in the ovarian maturation stages were compared. In addition, the effects of 5-hydroxytryptamine (5-HT) on the expression of PmMAT1 mRNA in the shrimp were examined.

\section{MATERIAL AND METHODS}

\section{Experimental animals}

Healthy black tiger shrimp ( $P$. monodon) with wet weight $80-200 \mathrm{~g}$ were collected from Shenzhen Base of South China Sea Fisheries Research Institute, Guang Dong Province, China, and acclimated in the aerated seawater (salinity 30 ) for 3 days at $28^{\circ}-30^{\circ} \mathrm{C}$. Tissues including muscle, hepatopancreas, heart, gill, cranial nerve, stomach, intestines, and ovary were dissected out, and snap-frozen in RNAlater (Invitrogen, Japan) at $-80^{\circ} \mathrm{C}$ before RNA extraction. Three shrimp in each ovarian mature stage were selected for RNA isolation from the ovary. Ovarian mature stage 1 (OV1) was considered a primordial germ cell stage, OV2 was chromatin nucleolus stage, OV3 was perinucleolus stage, OV4 was yolky stage, and OV5 was cortical rod stage (Huang et al., 2005).

For examining the effects of 5-HT on the expression of PmMAT1 mRNA, shrimp (average body weight $=82.42 \pm 4.15 \mathrm{~g}$ ) were reared in laboratory tanks containing aerated seawater (salinity 30) and fed ad libitum for a week to gradually acclimatize them to the laboratory conditions. The stimulation group was performed by injecting with $5-\mathrm{HT}(50 \mu \mathrm{g} / \mathrm{g}$ body weight) dissolved in 400 $\mathrm{mM} \mathrm{NaCl}, 10 \mathrm{mM}$ Tris- $\mathrm{HCl}, \mathrm{pH} 7.5$, into the first abdominal segment of each shrimp. The untreated shrimp and shrimp injected with $400 \mathrm{mM} \mathrm{NaCl}, 10 \mathrm{mM}$ Tris- $\mathrm{HCl}, \mathrm{pH} 7.5$, were used as blank and control group, respectively. The injected shrimp were returned to seawater tanks, and three individuals from the blank, control, and stimulated group, respectively, were randomly collected at $0,6,12,24$, and $48 \mathrm{~h}$ post-injection (hpi). At each time point, the ovaries from the three individuals were collected and mixed and total RNA was extracted from them.

\section{Total RNA isolation and first-strand cDNA synthesis}

Total RNA was extracted from the examined shrimp using TRIzol (Invitrogen) reagent following the manufacturer protocol, was dissolved in DEPC-treated water and stored at $-80^{\circ} \mathrm{C}$. RNA concentration was determined by UV spectrophotometry. First-strand cDNA was synthesized from $2 \mu \mathrm{g}$ total RNA by Moloney Murine Leukemia Virus reverse transcriptase (Promega, USA) at $42^{\circ} \mathrm{C}$ for 50 min with oligo-dT adaptor primer (5'-GGCCACGCGACTAGTAC $\left.(T)_{16}-3^{\prime}\right)$ following the manufacturer protocol. The cDNA was used as a template for polymerase chain reaction (PCR) to clone the gene. 


\section{Gene cloning and sequencing}

Gene-specific primers, MAT1-F/R (5'-CGTGCCATTCCTCTTGTG-3' and 5'-GGTCTTGTT GCGTTCTCG-3'), were designed based on the expressed sequence tag to clone the partial-sequence of MAT1 cDNA. The PCR cycling parameters were as follows: initial denaturation at $94^{\circ} \mathrm{C}$ for $3 \mathrm{~min}$, followed by 34 cycles at $94^{\circ} \mathrm{C}$ for $30 \mathrm{~s}, 51^{\circ} \mathrm{C}$ for $30 \mathrm{~s}$, and $72^{\circ} \mathrm{C}$ for $40 \mathrm{~s}$. The last cycle was followed by 10 min extension at $72^{\circ} \mathrm{C}$. The PCR product was purified by PCR purification kit (Sangon Biotech, China) and ligated to PMD18-T vector (TaKaRa Biotechnology, China). A portion of the ligation reaction product was transformed into $\mathrm{DH} 5 \alpha$ competent cells and the positive clones were picked for sequencing (Invitrogen).

Full-length PmMAT1 cDNA sequence was obtained by rapid amplification of cDNA ends (RACE) using BD SMART TM RACE CDNA amplification kit according to manufacturer instructions (Clontech Laboratories, USA). In 3'-RACE-PCR, PCR was performed initially with primer MSP1 (5'-CGAAACAGCAGACGAGTGGAACC-3') and UPM (0.4 $\mu \mathrm{M}$ UPX-long: 5'-CTAATACGACTCACTATAGGGCAAGCAGTGGTATCAACGCAGAGT-3' and $2 \mu \mathrm{M}$ UPXshort: 5'-CTAATACGACTCACTATAGGGC-3'), followed by semi-nested PCR with MSP2 (5'-GAAGTGGCAGGAAGAGGAGAATG-3') and NUP (5'-AAGCAGTGGTATCAACGCAGAGT-3'). The PCR products were gel-purified, sequenced, and the resulting sequences were analyzed.

The sequence of the obtained PmMAT1 cDNA was compared with other known sequences in the NCBI database using the BLAST program (Altschul et al., 1997). The pl value and molecular weight of the deduced MAT1 protein were examined using ProtParam (http://web.expasy.org/ protparam/). The N-glycosylation site was predicted using NetNGlyc 1.0 (http://www.cbs.dtu.dk/ services/NetNGlyc/). The Phosphorylation site was predicted using NetPhos 2.0 (http://www.cbs. $\mathrm{dtu} . \mathrm{dk} /$ services/NetPhos/). Multiple-sequence alignments were performed using the CLUSTAL W program. The protein domain in the deduced MAT1 protein was predicted using SMART (http:// smart.embl-heidelberg.de/). Phylogenetic tree was constructed by the neighbor-joining method using the CLUSTAL W program by comparison with the MAT1 protein and Mega5.0 program using the UPGMA method (Kumar et al., 2001; Larkin et al., 2007). Accession numbers of MAT1 used for sequence alignment and phylogenetic analyses were as follows: Sus scrofa (NP_001159788.1); Homo sapiens (NP_002422.1); Mus musculus (NP_032638.2); Picoides pubescens (KFV61905.1); Alligator mississippiensis (XP_006267935.1); Calypte anna (XP_008499322.1); Xenopus laevis (NP_001080361.1); Cynoglossus semilaevis (XP_008305760.1); Ictalurus punctatus (NP_001188073.1); Drosophila melanogaster(NP_610605.1); Ceratitiscapitata(XP_004537476.1); Bactrocera dorsalis (XP_011208383.1); Penaeus monodon (KP657569).

\section{RT-PCR and tissue distribution analysis}

Expression of PmMAT1 in different tissues in the black tiger shrimp was analyzed by reverse transcriptase (RT)-PCR with primers RTMAT1-F/R (5'-CGAACAACAGAAGGAAGAAC-3' and 5'-GCAGTGAAGGTGGAAGAT-3') and EF-F/R (5'-AAGCCAGGTATGGTTGTCAACTTT-3' and 5'-CGTGGTGCATCTCCACAGACT-3'). EF-1a (GenBank accession No. KM212954.1) amplified from the cDNA template of the same individuals was included as the positive control. The thermal amplification reaction was initially carried out at $94^{\circ} \mathrm{C}$ for 3 min followed by a 34-cycle denaturation at $94^{\circ} \mathrm{C}$ for $30 \mathrm{~s}$, annealing at $60^{\circ} \mathrm{C}$ for $30 \mathrm{~s}$ and extension at $72^{\circ} \mathrm{C}$ for $45 \mathrm{~s}$. The final extension was carried out at $72^{\circ} \mathrm{C}$ for $10 \mathrm{~min}$. The amplification product was stained with ethidium bromide and visualized under a UV transilluminator. 


\section{Quantitative real-time PCR}

Expression profiles of PmMAT1 in different tissues and ovarian maturation stages in black tiger shrimp were analyzed by quantitative real-time (qRT)-PCR performed on an Applied Light Cycler (Roche Diagnostics, Shanghai) using SYBR green. Specific primers, QMAT1-F/R (5'-GAAGGAAGAACAGGTGAAG-3' and 5'-GTGAAGGTGGAAGATTTGG-3'), were used to amplify a PCR product of about $167 \mathrm{bp}$. EF-1a was chosen as the reference gene for internal standardization, whereas CDK7-F/R (5'-TCTTTCCTGCTGCCAGTGAT-3' and 5'-GGACAGGCTTATTGCTGAAAT-3', GenBank accession No. FE043423.1) and cyclin H-F/R (5'-CGTGAGATTGAAGGCAAGTTAGA-3' and 5'-TTCCTGCATTGGGGAAGC-3', GenBank accession No. AGP03382.1) were used for comparative analysis. A $10-\mu \mathrm{L}$ reaction volume contained $5 \mu \mathrm{L}$ 2X LightCycler 480 SYBR Green I Master (Roche Diagnostics), 50 ng first-strand cDNA template, and $0.2 \mu \mathrm{M}$ each primer. The thermal profile for qRT-PCR was $95^{\circ} \mathrm{C}$ for $30 \mathrm{~s}$ followed by 40 cycles at $95^{\circ} \mathrm{C}$ for $5 \mathrm{~s}, 60^{\circ} \mathrm{C}$ for $20 \mathrm{~s}$. Real-time PCR of each specimen was carried out in duplicate.

\section{Statistical analysis}

The comparative Ct method (Qiu et al., 2010) was used to analyze the expression level of the PmMAT1 gene. The data obtained from qRT-PCR analysis were subjected to one-way analysis of variance (one-way ANOVA, SPSS 22.0). Differences were considered significant at $P<0.05$.

\section{RESULTS}

\section{Isolation and characterization of full-length PmMAT1 cDNA}

The full-length PmMAT1 cDNA (GenBank accession No. KP657569) was 1490 bp in length and contained an open reading frame (ORF) of 993 bp with 5'- and 3'-UTRs of 70 and 427 $\mathrm{bp}$, respectively. The isolated cDNA was predicted to encode a peptide of 330 amino acids with a calculated molecular mass of $38.9 \mathrm{kDa}$ and a theoretical pl of 5.41 . Bioinformatic analysis of the deduced polypeptide sequence identified several significant domains or motifs. The deduced amino acid of PmMAT1 contained a conserved RING finger domain (Cys13-Cys56), two coiled-coil regions (Glu133-Asp161, Val205-Glu238), a low complexity region (Pro266-Pro276), 4 N-glycosylation sites, 21 phosphorylation sites including $10 \mathrm{Ser}, 1 \mathrm{Thr}$, and $10 \mathrm{Tyr}$ residues (Figures 1 and 2). Signal P 4.0 analysis revealed that PmMAT1 did not contain a typical signal peptide sequence. The result of multiple-sequence alignment suggested that PmMAT1 was highly homologous with MAT1 of the different eukaryote species and shared a highly conserved RING finger domain (Figure 3). The dendrogram (Figure 4) depicted the evolutionary relationship based on the similarity of MAT1 proteins from the different species. The MAT1 of black tiger shrimp and insects were grouped in one cluster, and those of insect and vertebrate were grouped in another cluster.

\section{Tissue expression analysis of PmMAT1}

RT-PCR indicated that the expression levels of PmMAT1 in different tissues of shrimp were comparable. Tissue distribution analysis further indicated that PmMAT1 was abundantly 


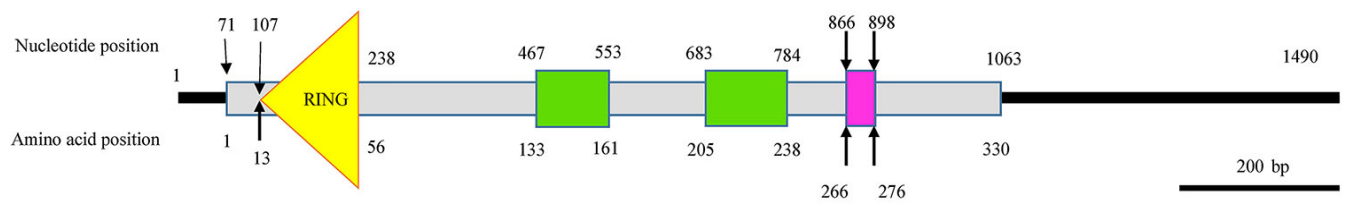

Figure 1. Schematic diagram representing the full-length cDNA of PmMAT1. The predicted RING domain (positions 13-56) in the deduced PmMAT1 protein is indicated by the triangle.

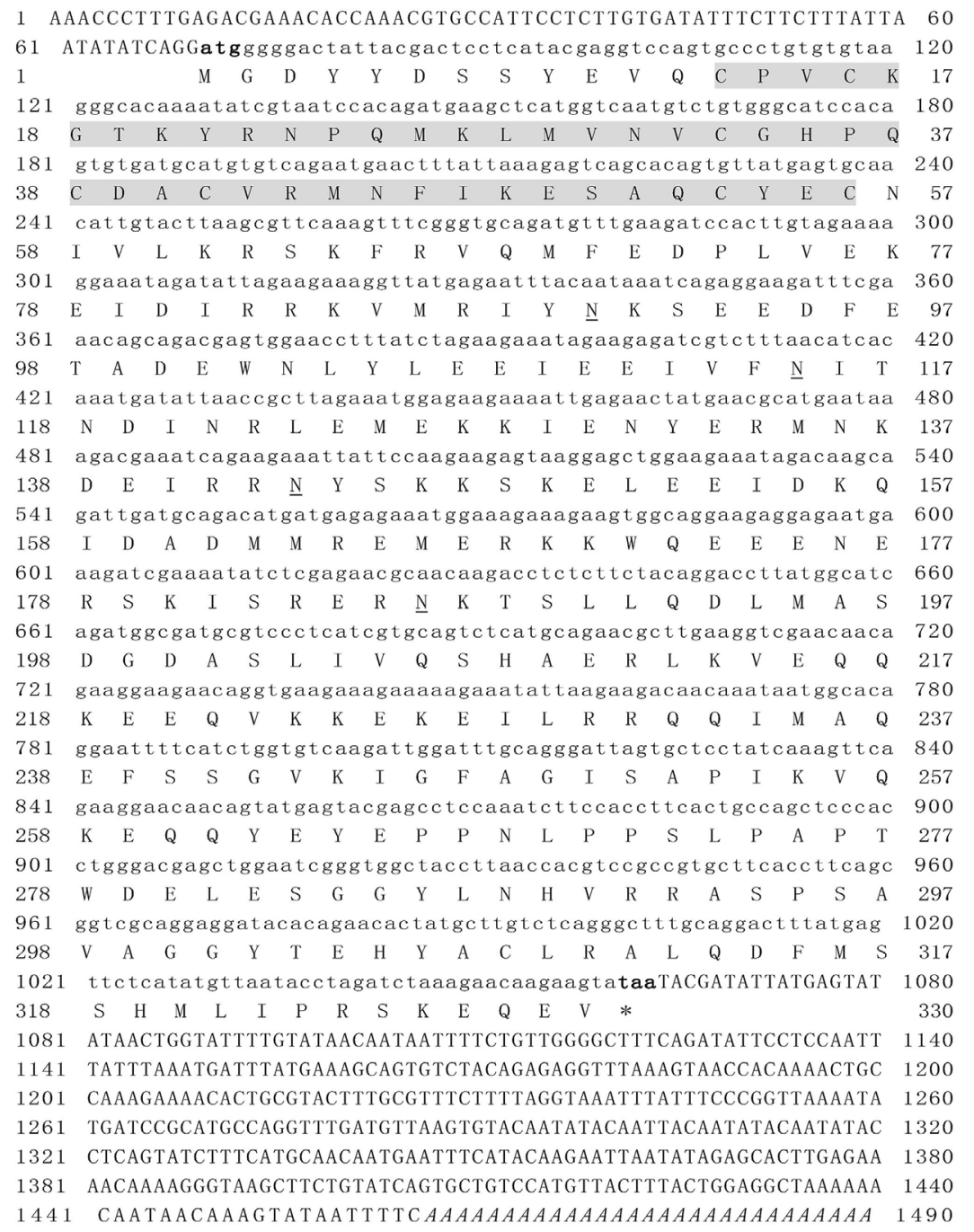

Figure 2. Nucleotide and deduced amino acid sequence of full-length PmMAT1 cDNA. Numbers on the left and right of each row refer to the nucleotide or amino acid position. The initiation codon (ATG) and the termination codon (TAA) are indicated in bold font. The poly A signal sequence is italicized. The RING finger domain is highlighted. Potential $\mathrm{N}$-glycosylation sites are underlined. 


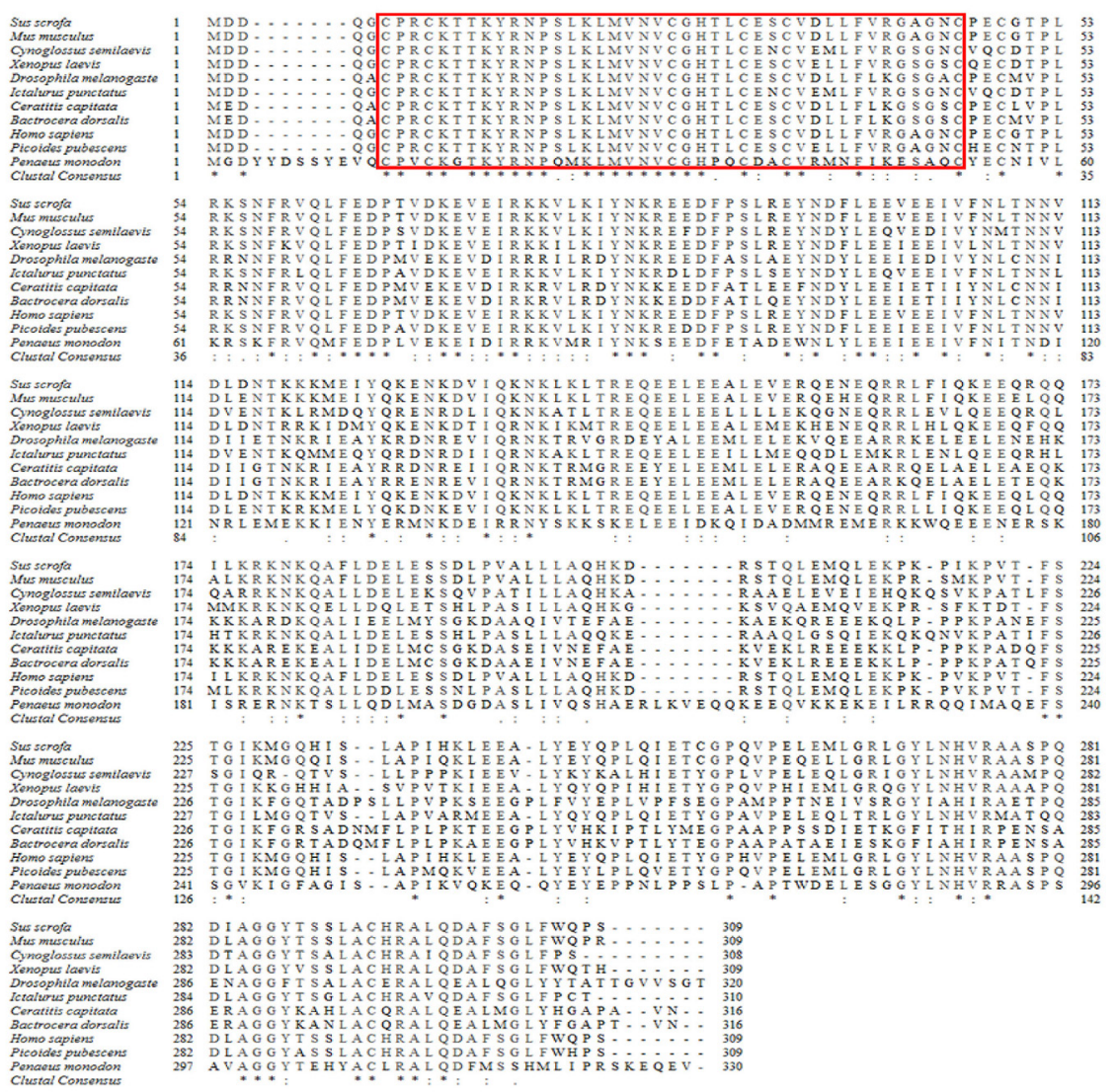

Figure 3. Multiple alignments of PmMAT1 with other known MAT1 amino acid sequences aligned using the CLUSTAL W program. Identical and similar sites are indicated with asterisks and dots or colons, respectively. Box marked in red encompasses the conserved RING finger domain in different species.

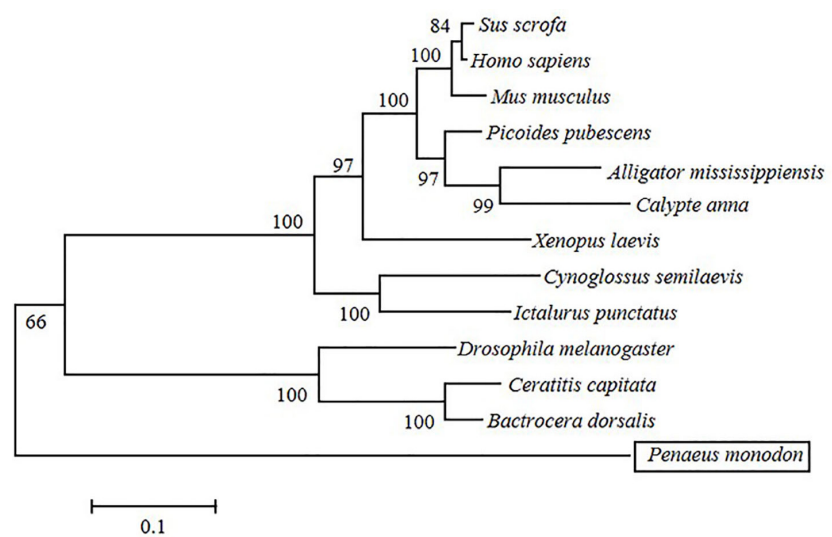

Figure 4. Bootstrapping phylogenetic tree of MAT1 proteins from different species generated by CLUSTAL W and Mega program using the UPGMA method. Values at the node represent the percentage of times the particular node occurred in 1000 trees generated by bootstrapping the original aligned sequences. 
expressed in ovaries, hepatopancreas, and muscles. Low expression levels of PmMAT1 were observed in other tissues including heart, stomach, gill, intestines, and cranial nerve of female shrimp (Figure 5).

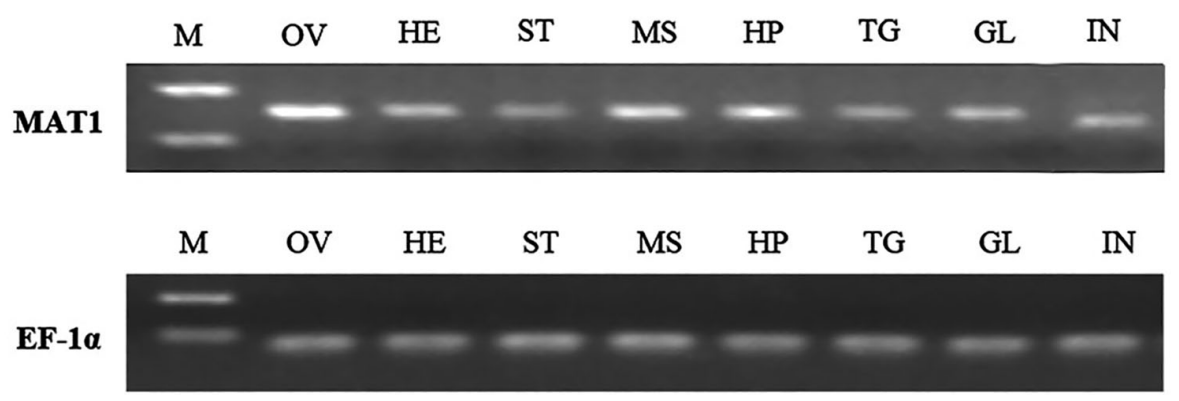

Figure 5. RT-PCR of PmMAT1 using the first-strand cDNA from tissues of Penaeus monodon. Maker (M), ovaries (OV), heart (HE), stomach (ST), muscle (MS), hepatopancreas (HP), thoracic ganglion (TG), gill (GL), and intestine (IN).

\section{Expression profiles of PmMAT1 in P. monodon}

Results from qRT-PCR indicated that PmMAT1 was constitutively expressed in all the examined tissues with significant variation in the expression levels in the shrimp. The expression level of PmMAT1 in ovary, hepatopancreas, and muscle was high whereas it was low in the heart, stomach, gill, cranial nerve, and intestines. The highest level of PmMAT1 expression was detected in ovary, showing approximately 2-fold the expression observed in the hepatopancreas (Figure 6A). The PmMAT1 transcripts were constitutively expressed in ovary but the expression varied during the maturation stages. The expression level of PmMAT1 sharply increased in OV3 while it was very low in the other stages (Figure 6B).

\section{Expression profiles of MAT1, CDK7, and cyclin $H$ in maturation stages of ovaries in $P$. monodon}

The expression levels of CDK7 and cyclin $\mathrm{H}$ sharply increased in the second to the third stage and decreased in the fourth stage. Multiple comparison of the three expression characters showed that the levels of CDK7 and cyclin $\mathrm{H}$ followed the same trend of variation as the expression features of MAT1 during the maturation stages of ovaries (Figure 6C).

\section{Effects of 5-HT injection on PmMAT1 transcription in ovaries of $P$. monodon}

The effects of 5-HT on the expression of PmMAT1 in ovaries of $P$. monodon were examined. The expression level of PmMAT1 gradually increased at 6-48 hpi, and reached the highest level at 48 hpi (Figure 7).

\section{DISCUSSION}

The present study reports the cloning and characterization of a full-length MAT1 cDNA in 

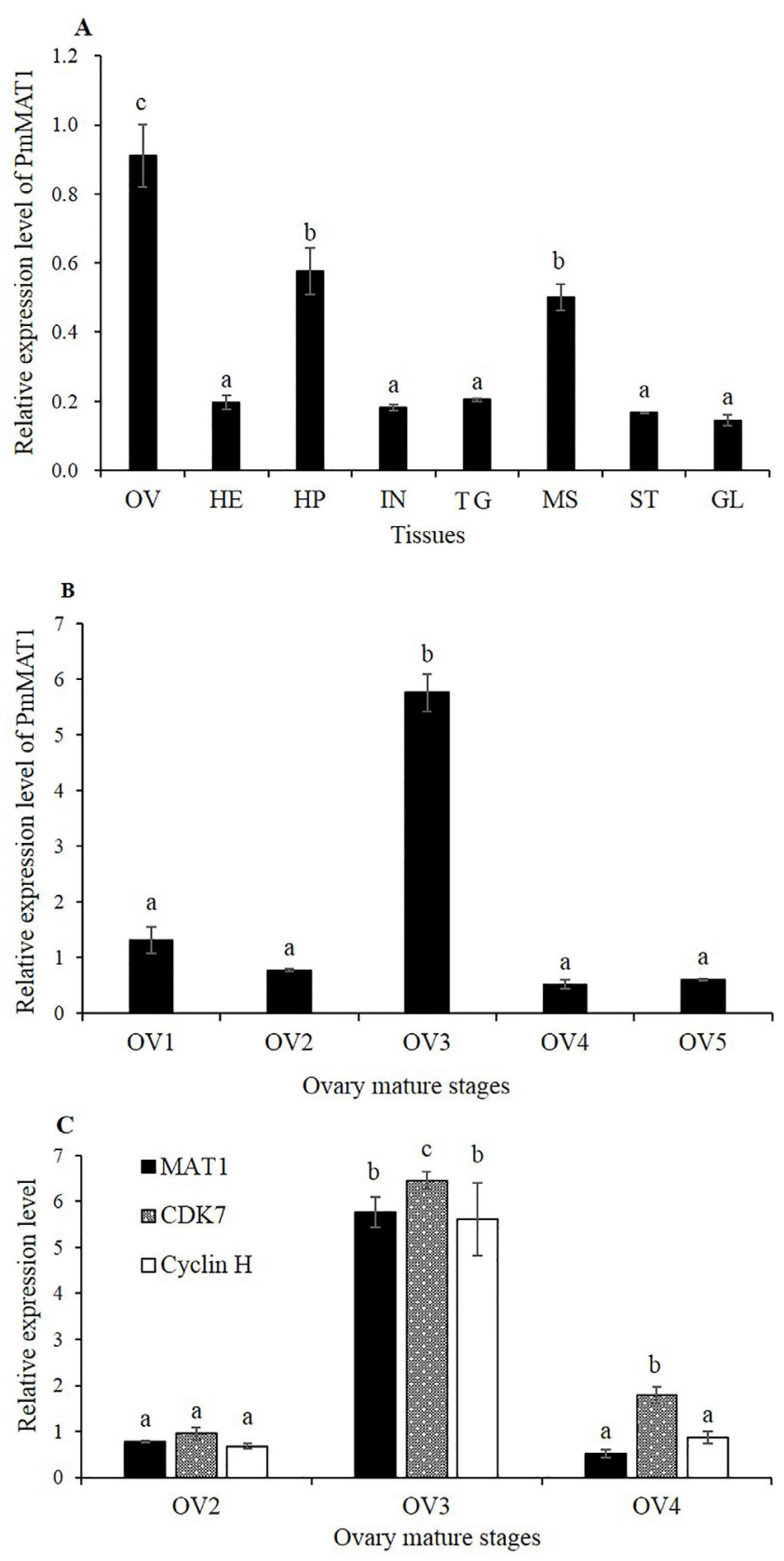

Figure 6. qRT-PCR analysis of PmMAT1 expression levels in different tissues of Penaeus monodon. Relative expression levels of MAT1 in different tissues (A). Relative expression levels of MAT1 in the different maturation stages of ovary (B). Relative expression levels of $M A T 1, C D K 7$, and cyclin $H$ in ovarian maturation stages (C). OV1: primordial germ cell stage; OV2: chromatin nucleolus stage; OV3: perinucleolus stage; OV4: yolky stage; OV5: cortical rod stage. Vertical bars represent means $\pm S E(N=3)$. Bars with different letters $(a, b$, and $c)$ differed significantly $(P<0.05)$. For tissue abbreviations, see Figure 5. 


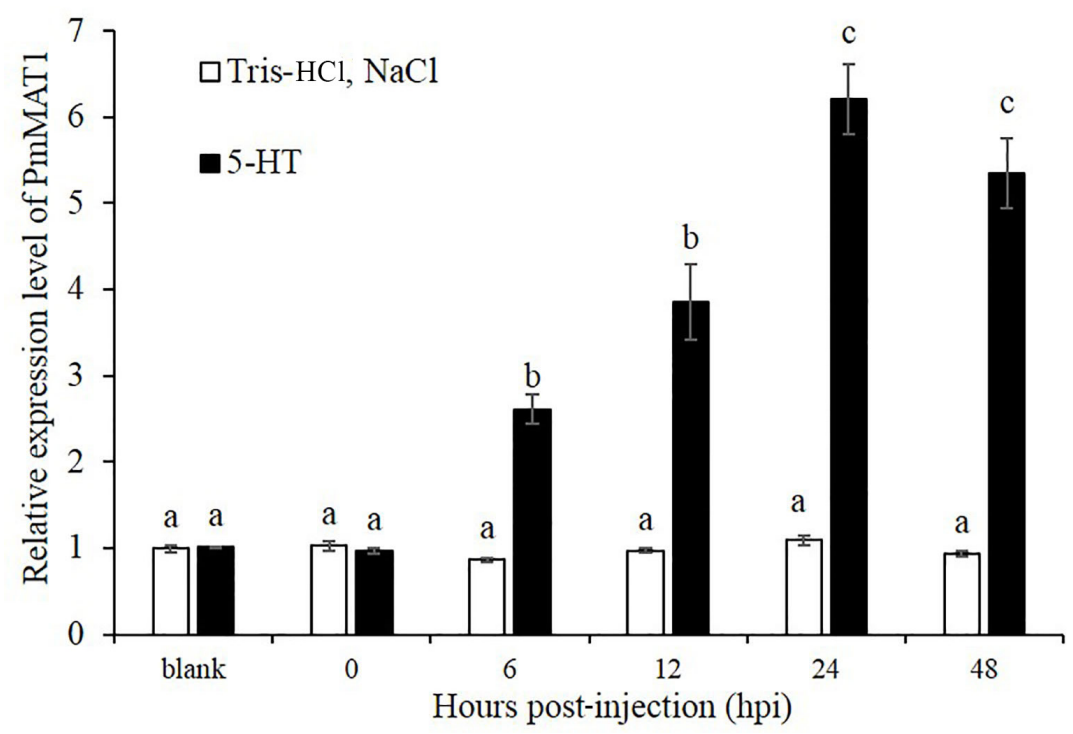

Figure 7. qRT-PCR analysis of the PmMAT1 expression levels after 5-HT stimulation in ovary. Vertical bars represent means $\pm S E(N=3)$. Bars with different letters $(a, b, c)$ differed significantly $(P<0.05)$.

black tiger shrimp ( $P$. monodon) using the RACE technique. The full length of this cDNA was 1490 bp and included an ORF of 993 nucleotides encoding a polypeptide of 330 amino acids with an estimated molecular mass of about $38.9 \mathrm{kDa}$. As shown in Figures 1 and 2, there was one RING finger domain, two coiled-coil regions, and a low-complexity region. Multiple-sequence alignment suggested that PmMAT1 was highly homologous to MAT1 of different eukaryote species and shared a highly conserved RING finger domain (Figure 3). The deduced amino acids of PmMAT1 showed moderate similarity to MAT1 from other organisms, such as C. capitata (positive 44\%, E-value = 7e-74), B. dorsalis (positive 41\%, E-value $=3 e-73$ ), and $P$. pubescens (positive 43\%, E-value = 5e-82). The $E$-value were all lower than 0.005 . If the $E$-value is lower than 0.005 , the sequences are considered homologous (Anderson and Brass, 1998). The phylogenetic tree demonstrated that the target gene was clustered with that of arthropod (Figure 4). These conserved characteristics together proved that PmMAT1 belonged to the MAT1 family. The RING finger domain is conserved from invertebrates to vertebrates (Figure 3 ) and appears to be involved in transcription activation and CTD phosphorylation (Busso et al., 2000). In the MAT1-deficient trophoblast cells, MAT1 regulates the CTD phosphorylation levels in vivo either by affecting the activity of CDK7-Cyclin $\mathrm{H}$ kinase directly or by modifying the activities of the other CTD kinases (Korsisaari, 2002). The central coiled-coil motif was primarily suggested to mediate CDK7-Cyclin H-MAT1 binding with the core TFIIH through interactions with XPD and XPB (Rossignol et al., 1997; Busso et al., 2000; Sandrock and Egly, 2001). The MAT1 polypeptide in black tiger shrimp contained two coiled-coil regions while in others it contains only one. This difference in the structure implies variance in their functions. The low complexity region (LCR) may be involved in flexible binding associated with specific functions. LCR-containing proteins tend to have more binding partners across different protein-protein interaction networks than proteins that have no LCR (Coletta et al., 2010). LCRs exhibit a variety of puzzling evolutionary phenomena (DePristo et al., 2006). In vertebrate MAT1, there is no LCR, which indicates that PmMAT1 plays a novel role in the CAK complex in black tiger 
shrimp. CAK regulates cell cycle progression by activating CDK complexes through phosphorylation of a critical threonine residue in their T-loop domain (Sherr, 1994; Morgan, 1995), whereas MAT1 functions in the cell cycle by stabilizing the association of CDK7 with cyclin H (Devault et al., 1995; Fisher et al., 1995; Tassan et al., 1995) and determining the substrate specificity of CDK7-cyclin H (Ko et al., 1997; Rossignol et al., 1997; Yankulov and Bentley, 1997). Therefore, our data strongly indicate that the identified MAT1 gene might be related to cell proliferation in black tiger shrimp, both mitotically and meiotically.

The development of oocytes involves a series of complex cellular events, in which different genes are expressed to ensure the proper development of oocytes and to store transcripts and proteins as maternal factors for early embryogenesis (Qiu et al., 2005; Phinyo et al., 2014). In the present study, the mRNA expression of black tiger shrimp MAT1 could be detected in all the tested tissues (Figure 5). The highest level of MAT1 mRNA expression was detected in the ovary (Figure 6A), which was consistent with the fact that there is massive cell proliferation during ovarian development and maturation. In other tissues, PmMAT1 was abundantly expressed in hepatopancreas and muscles (Figure 6A). This could mean that PmMAT1 is related to the growth and metabolism in black tiger shrimp. Therefore, PmMAT1 may be concerned with the growth in the black tiger shrimp, and it may play a more important role in oogenesis (and ovarian development) than in other tissues of $P$. monodon. The results of genetic mutations in mouse MAT1 revealed an absolute requirement for MAT1 both in the mitotic embryonic inner cell mass and adult germ cells (Korsisaari, 2002). To further understand the possible biological function of the PmMAT1, its temporal expression pattern was quantified during the different maturation stages of ovaries by qRT-PCR. We observed that the abundance of MAT1 mRNA increased sharply in the third stage (perinucleolus stage; Figure $6 \mathrm{~B}$ ). In the first stage, the ovary did not begin to grow; in the fifth stage, the development of the ovary began to end; and from the second to the fourth stage, the ovary was in the developmental phase. This result suggested that the cloned PmMAT1 gene should play a critical role in development during the ovarian stages. To better understand the function of the MAT1 in the CAK complex, comparative analysis of CDK7 and cyclin $\mathrm{H}$ expression in the ovaries was conducted. The expression levels of $C D K 7$ and cyclin $\mathrm{H}$ coincided with those of MAT1 in the maturation stages of the ovary (Figure 6C). CDK7 with its cyclin partner, cyclin $\mathrm{H}$, and a third subunit MAT1 has been implicated in positive regulation of the other CDK-cyclins in vitro (Korsisaari, 2002). MAT1 was required to achieve the normal levels of CDK7 and cyclin $\mathrm{H}$ protein in cardiac muscles and to recruit the kinase complex to the core components of TFIIH (Sano et al., 2007). Deleting MAT1 in myocardium severely impaired CDK7 activity, both as a free heterodimer and as a part of TFIIH (Sano et al., 2007). Therefore, it can be concluded that the MAT1 plays a significant role in the CAK complex regulating cell cycle progression in black tiger shrimp.

The stimulation of ovarian maturation and spawning by 5 -HT has been reported in $P$. monodon (Wongprasert et al., 2006). To further understand the potential function of PmMAT1 in $P$. monodon. We injected shrimp with the same amount of 5-HT and found that 5-HT enhanced the expression level of PmMAT1 at 6-48 hpi (Figure 7). Likewise, 5-HT injection (50 mg/g body weight) resulted in the up-regulation of $P m C d c 2$, which is functionally involved in meiotic maturation of oocytes, at $1 \mathrm{hpi}$ (Phinyo et al., 2013) and PmCDK7, which is functionally important in ovarian development, fertilization, and embryo development in P. monodon (Phinyo et al., 2014). Results obtained in the present study confirmed the molecular effects of 5-HT on the transcription of genes functionally involved in the signal transduction and indicated that 5-HT might directly enhance the meiotic maturation of oocytes in P. monodon by stimulation of the MPF (a complex of Cdc2 and 
cyclin B) via the activity of CAK (PmMAT1, CDK7, and cyclin $\mathrm{H}$ ).

Loss of MAT1 is associated with the loss of TFIIH kinase activity and destabilization of CDK7 and cyclin $\mathrm{H}$. The observed general transcription defect in the MAT1-deficient cells, therefore, may be partly mediated through direct decreased activation of elongation factors by CDK7 (Helenius et al., 2011). In mammalian cellular models, CAK is involved in the regulation of cell cycle G1 exit while MAT1-modulated CAK formation and CAK phosphorylation of pRb may determine the cell cycle specificity of CAK in the G1 progression (Wu et al., 2001). Manipulation of MAT1 abundance shows that MAT1 reduction mimics retinoic acid-induced hypophosphorylation of $p R b / R X R \alpha$, proliferation inhibition, and neurite outgrowth, whereas MAT1 overexpression resists these retinoic acid actions, which reveal an important mechanism by which MAT1-modulated CAK activity is crucial in the switch from proliferation to differentiation in neuroblastoma cells (Zhang et al., 2004).

In conclusion, PmMAT1 might play a functional role in the development of oocytes in $P$. monodon. The basic knowledge obtained in this study will allow the characterization of the function of PmMAT1 in the control of oocyte maturation in this economically important species. However, the MAT1 gene regulation mechanism should be explored further in a more comprehensive study.

\section{Conflicts of interest}

The authors declare no conflict of interest.

\section{ACKNOWLEDGMENTS}

Research supported by the National "863" Program (\#2012AA10A409), China Agriculture Research System (\#CARS-47); the National Natural Science Foundation of China (31201976), the Special Fund for Fisheries-Scientific Research of Guangdong Province (\#A201300B03); the Guangdong Provincial Science and Technology Program (\#2013B040402016); the Key Science and Technology Plan Projects of Hainan Province (\#ZDXM2014057); the Special Scientific Research Funds for Central Non-Profit Institutes, South China Sea Fisheries; the Research Institute, Chinese Academy of Fishery Sciences (\#2015YD05); and the Guangdong Provincial Science and Technology Program (\#2014A020208039).

\section{REFERENCES}

Altschul SF, Madden TL, Schäffer AA, Zhang J, et al. (1997). Gapped BLAST and PSI-BLAST: a new generation of protein database search programs. Nucleic Acids Res. 25: 3389-3402.http://dx.doi.org/10.1093/nar/25.17.3389

Anderson I and Brass A (1998). Searching DNA databases for similarities to DNA sequences: when is a match significant? Bioinformatics 14: 349-356.http://dx.doi.org/10.1093/bioinformatics/14.4.349

Benzie JAH (1998). Penaeid genetics and biotechnology. Aquaculture 164: 23-47. http://dx.doi.org/10.1016/S00448486(98)00175-6

Busso D, Keriel A, Sandrock B, Poterszman A, et al. (2000). Distinct regions of MAT1 regulate cdk7 kinase and TFIIH transcription activities. J. Biol. Chem. 275: 22815-22823.http://dx.doi.org/10.1074/jbc.M002578200

Coletta A, Pinney JW, Solís DY, Marsh J, et al. (2010). Low-complexity regions within protein sequences have positiondependent roles. BMC Syst. Biol. 4: 43.http://dx.doi.org/10.1186/1752-0509-4-43

DePristo MA, Zilversmit MM and Hartl DL (2006). On the abundance, amino acid composition, and evolutionary dynamics of low-complexity regions in proteins. Gene 378: 19-30.http://dx.doi.org/10.1016/..gene.2006.03.023

Devault A, Martinez AM, Fesquet D, Labbé JC, et al. (1995). MAT1 ('menage à trois') a new RING finger protein subunit stabilizing cyclin $\mathrm{H}$-cdk7 complexes in starfish and Xenopus CAK. EMBO J. 14: 5027-5036.

Fisher RP and Morgan DO (1994). A novel cyclin associates with MO15/CDK7 to form the CDK-activating kinase. Cell 78: 713- 
724.http://dx.doi.org/10.1016/0092-8674(94)90535-5

Fisher RP, Jin P, Chamberlin HM and Morgan DO (1995). Alternative mechanisms of CAK assembly require an assembly factor or an activating kinase. Cell 83: 47-57.http://dx.doi.org/10.1016/0092-8674(95)90233-3

Helenius K, Yang Y, Alasaari J and Mäkelä TP (2009). Mat1 inhibits peroxisome proliferator-activated receptory-mediated adipocyte differentiation. Mol. Cell. Biol. 29: 315-323.http://dx.doi.org/10.1128/MCB.00347-08

Helenius K, Yang Y, Tselykh TV, Pessa HK, et al. (2011). Requirement of TFIIH kinase subunit Mat1 for RNA Pol II C-terminal domain Ser5 phosphorylation, transcription and mRNA turnover. Nucleic Acids Res. 39: 5025-5035.http://dx.doi. org/10.1093/nar/gkr107

Hoeijmakers JH, Egly JM and Vermeulen W (1996). TFIIH: a key component in multiple DNA transactions. Curr. Opin. Genet. Dev. 6: 26-33.http://dx.doi.org/10.1016/S0959-437X(96)90006-4

Huang JH, Zhou FL, Ma ZM and Jiang SG (2005). Morphological and histological observation on ovary development of Penaeus monodon from northern South China Sea. J. Trop. Oceanogr. 25: 47-52.

Inamoto S, Segil N, Pan ZQ, Kimura M, et al. (1997). The cyclin-dependent kinase-activating kinase (CAK) assembly factor, MAT1, targets and enhances CAK activity on the POU domains of octamer transcription factors. J. Biol. Chem. 272: 29852-29858.http://dx.doi.org/10.1074/jbc.272.47.29852

Kaldis P (1999). The cdk-activating kinase (CAK): from yeast to mammals. Cell. Mol. Life Sci. 55: 284-296.http://dx.doi. org/10.1007/s000180050290

Kaldis P, Russo AA, Chou HS, Pavletich NP, et al. (1998). Human and yeast cdk-activating kinases (CAKs) display distinct substrate specificities. Mol. Biol. Cell 9: 2545-2560.http://dx.doi.org/10.1091/mbc.9.9.2545

Ko LJ, Shieh S-Y, Chen X, Jayaraman L, et al. (1997). p53 is phosphorylated by CDK7-cyclin H in a p36MAT1-dependent manner. Mol. Cell. Biol. 17: 7220-7229.http://dx.doi.org/10.1128/MCB.17.12.7220

Korsisaari N (2002). Functional analysis of Cdk7-interacting proteins Mat1 and Hint in model organisms. Academic Dissertation, University of Helsinki, Finland.

Kumar S, Tamura K, Jakobsen IB and Nei M (2001). MEGA2: molecular evolutionary genetics analysis software. Bioinformatics 17: 1244-1245.http://dx.doi.org/10.1093/bioinformatics/17.12.1244

Larkin MA, Blackshields G, Brown NP, Chenna R, et al. (2007). Clustal W and Clustal X version 2.0. Bioinformatics 23: 29472948.http://dx.doi.org/10.1093/bioinformatics/btm404

Levedakou EN, He M, Baptist EW, Craven RJ, et al. (1994). Two novel human serine/threonine kinases with homologies to the cell cycle regulating Xenopus MO15, and NIMA kinases: cloning and characterization of their expression pattern. Oncogene 9: 1977-1988.

Morgan DO (1995). Principles of CDK regulation. Nature 374: 131-134.http://dx.doi.org/10.1038/374131a0

Nigg EA (1996). Cyclin-dependent kinase 7: at the cross-roads of transcription, DNA repair and cell cycle control? Curr. Opin. Cell Biol. 8: 312-317.http://dx.doi.org/10.1016/S0955-0674(96)80003-2

Patel SA and Simon MC (2010). Functional analysis of the Cdk7.cyclin H.Mat1 complex in mouse embryonic stem cells and embryos. J. Biol. Chem. 285: 15587-15598.http://dx.doi.org/10.1074/jbc.M109.081687

Phinyo M, Visudtiphole V, Roytrakul S, Phaonakrop N, et al. (2013). Characterization and expression of cell division cycle 2 (Cdc2) mRNA and protein during ovarian development of the giant tiger shrimp Penaeus monodon. Gen. Comp. Endocrinol. 193: 103-111.http://dx.doi.org/10.1016/j.ygcen.2013.07.012

Phinyo M, Nounurai P, Hiransuchalert R, Jarayabhand P, et al. (2014). Characterization and expression analysis of Cyclindependent kinase 7 gene and protein in ovaries of the giant tiger shrimp Penaeus monodon. Aquaculture 432: 286-294. http://dx.doi.org/10.1016/j.aquaculture.2014.05.022

Qiu GF, Yamano K and Unuma T (2005). Cathepsin C transcripts are differentially expressed in the final stages of oocyte maturation in kuruma prawn Marsupenaeus japonicus. Comp. Biochem. Physiol. B Biochem. Mol. Biol. 140: 171-181. http://dx.doi.org/10.1016/j.cbpc.2004.09.027

Qiu L, Ma Z, Jiang S, Wang W, et al. (2010). Molecular cloning and mRNA expression of peroxiredoxin gene in black tiger shrimp (Penaeus monodon). Mol. Biol. Rep. 37: 2821-2827.http://dx.doi.org/10.1007/s11033-009-9832-8

Rossi DJ, Londesborough A, Korsisaari N, Pihlak A, et al. (2001). Inability to enter S phase and defective RNA polymerase II CTD phosphorylation in mice lacking Mat1. EMBO J. 20: 2844-2856.http://dx.doi.org/10.1093/emboj/20.11.2844

Rossignol M, Kolb-Cheynel I and Egly JM (1997). Substrate specificity of the cdk-activating kinase (CAK) is altered upon association with TFIIH. EMBO J. 16: 1628-1637.http://dx.doi.org/10.1093/emboj/16.7.1628

Sandrock B and Egly JM (2001). A yeast four-hybrid system identifies Cdk-activating kinase as a regulator of the XPD helicase, a subunit of transcription factor IIH. J. Biol. Chem. 276: 35328-35333.http://dx.doi.org/10.1074/jbc.M105570200

Sano M, Izumi Y, Helenius K, Asakura M, et al. (2007). Ménage-à-trois 1 is critical for the transcriptional function of PPARgamma coactivator 1. Cell Metab. 5: 129-142.http://dx.doi.org/10.1016/j.cmet.2007.01.003

Sherr CJ (1994). G1 phase progression: cycling on cue. Cell 79: 551-555.http://dx.doi.org/10.1016/0092-8674(94)90540-1 
Tassan JP, Jaquenoud M, Fry AM, Frutiger S, et al. (1995). In vitro assembly of a functional human CDK7-cyclin $\mathrm{H}$ complex requires MAT1, a novel $36 \mathrm{kDa}$ RING finger protein. EMBO J. 14: 5608-5617.

Wongprasert K, Asuvapongpatana S, Poltana P, Tiensuwan M, et al. (2006). Serotonin stimulates ovarian maturation and spawning in the black tiger shrimp Penaeus monodon. Aquaculture 261: 1447-1454. http://dx.doi.org/10.1016/j. aquaculture.2006.08.044

Wu L, Yee A, Liu L, Carbonaro-Hall D, et al. (1994). Molecular cloning of the human CAK1 gene encoding a cyclin-dependent kinase-activating kinase. Oncogene 9: 2089-2096.

Wu L, Chen P, Shum CH, Chen C, et al. (2001). MAT1-modulated CAK activity regulates cell cycle G(1) exit. Mol. Cell. Biol. 21: 260-270.http://dx.doi.org/10.1128/MCB.21.1.260-270.2001

Yankulov KY and Bentley DL (1997). Regulation of CDK7 substrate specificity by MAT1 and TFIIH. EMBO J. 16: 1638-1646. http://dx.doi.org/10.1093/emboj/16.7.1638

Yee A, Nichols MA, Wu L, Hall FL, et al. (1995). Molecular cloning of CDK7-associated human MAT1, a cyclin-dependent kinase-activating kinase (CAK) assembly factor. Cancer Res. 55: 6058-6062.

Zhang S, He Q, Peng H, Tedeschi-Blok N, et al. (2004). MAT1-modulated cyclin-dependent kinase-activating kinase activity cross-regulates neuroblastoma cell G1 arrest and neurite outgrowth. Cancer Res. 64: 2977-2983.http://dx.doi. org/10.1158/0008-5472.CAN-03-4018 